\title{
Investigation on the Current Situation of College Students' Phonetic Acquisition and Its Implications for English Phonetic Teaching*
}

\author{
Chunhua Zheng \\ Wuchang Shouyi University \\ Wuhan, China
}

\begin{abstract}
As one of the basic skills of English learning, phonetics learning is very important in the process of English language acquisition. Through a questionnaire survey of nonEnglish majors and English teachers in three private universities in Hubei Province, it is found that students are subjectively aware of the importance of phonetic learning and are very dissatisfied with their phonetic status, but their efforts are far from enough. Teachers also have a good understanding of the importance of students' phonetics acquisition, but they do not pay enough attention to students' phonetic learning in actual teaching. Based on the questionnaire survey and the phonetic teaching experiment, this paper analyzes the current situation of non-English majors' phonetic acquisition in private colleges and universities and the problems and reasons in the phonetic learning, discusses the feasible coping strategies, and further puts forward the suggestions of phonetic teaching.
\end{abstract}

Keywords-private colleges; college students; phonetic acquisition; phonetic teaching

\section{INTRODUCTION}

Pronunciation is the foundation of the entire language system and a prerequisite for language knowledge and language skills. Gimson, a famous British phonetician, once said, "In any language, people need to master almost $100 \%$ phonetics knowledge, while for grammar knowledge they only needs to master $50 \%-90 \%$, and for vocabulary only $1 \%$ is needed. (Crutdenden, 2001). If the student can't discern the smallest phonetic unit, he can't distinguish the words he hears in the process of "listening", so they can't correctly imitate and read the words. In the process of "speaking", he can't accurately say what he wants to expressed. In addition, from the communication itself, accurate, smooth and clear voice can ensure that the other party accurately and easily understand what they mean, and thus achieve the purpose of communication. Therefore, to learn a foreign language comprehensively and firmly one should first master the pronunciation.

*This article is part of the results of the 2017 Provincial Teaching Research Project of the Higher Education Institution of Hubei Province: "The Construction and Effectiveness of the College English Leveling and Diversified Evaluation System against the Background of Learning Output Concept", Project No. 2017499
However, for a long time, the English enlightenment of English learners in China is relatively late. The English learning in the primary and senior high schools is mainly based on exam-oriented education, with emphasis on grammar, vocabulary, reading and writing, neglecting the pronunciation learning. In addition, there is no clear requirement for phonetic knowledge in various tests. A considerable number of students pay less attention to phonetic learning. As a result, students have a weak phonetic foundation and poor pronunciation habits. At the same time, students' phonetic learning is also affected by the negative transfer of their mother tongue. In the current college English teaching in China, the phonetic teaching has not received required attention. These factors restrict the effective learning of college students' English pronunciation.

In recent years, with the increasing number of English learners in China, the increasing importance of English learning and the continuous development of foreign language teaching concepts, the learner's practical application ability of language has been continuously concerned by the society, as the initial and most superficial expression way of language, the position of phonetics in the vocal communication is more and more prominent. More and more experts and scholars as well as front-line teachers have conducted multi-level and multi-faceted research on phonetic acquisition. There are more studies on phonetics and phonology using second language acquisition theory for problems existing in the pronunciation learning of English learners in China. However, what is the degree of attention paid by students to the pronunciation and intonation in the pronunciation acquisition of non-English majors? What is the current state of language acquisition? Does the teaching condition meet the needs of phonetic learning? What are the teachers' emphasis on phonetic teaching and what measures are taken? All these questions require further answers. The author works in an ordinary private college, and the language foundation of the students is weaker. Therefore, this paper conducts surveys through questionnaires, teaching experiments and interviews to discover the current situation, problems and causes of English phonetics acquisition in private colleges and universities, find corresponding countermeasures, and provide some guidance for phonetic teaching of college English. 


\section{RESEARCH DESIGN}

This paper uses questionnaires, teaching experiments and personal interviews to conduct a questionnaire survey of non-English majors and college English teachers in three private universities in Hubei Province. The purpose is to understand the current situation of students' phonetic acquisition, the importance of phonetic learning and the awareness of phonetic knowledge. At the same time, we also want to understand the importance of college English teachers' emphasis on speech, the importance of phonetic teaching, and the strategies and methods adopted for phonetic teaching. At the same time, the author opened an English phonetic elective course in the school and embedded phonetic teaching module in college English listening and speaking course to supplement the students' phonetic knowledge. After the elective course and the phonetics embedding teaching, the comprehensive analysis was made on 250 college students' English phonetics through the course investigation from the acquisition of segmental phoneme and the acquisition of super-segmental phoneme, and a large number of data were obtained. In addition, the author randomly sampled 30 students from the electives to write a course summary and conducted face-toface interviews on some issues.

\section{A. Questionnaire Design and Phonetic Teaching Experiment}

In order to understand the degree of cognition of students and teachers on phonetic learning, the author designed questionnaires for students and teachers respectively. The questionnaires for students are mainly about 1) the importance of phonetic learning and the degree of emphasis 2) satisfaction with the status quo of their own voice 3) the cognition degree of the phonetic system 4) satisfaction with school phonetic teaching There are 20 questions in four aspects. The questionnaire for teachers is mainly about 1) the teacher's own mastery of phonetic knowledge 2) the emphasis on phonetic teaching 3) phonetic teaching methods and strategies in their English teaching. There are 15 questions in three aspects. In the English speech elective course and phonetic module embedded listening and speaking classroom, the author mainly carried out intensive training on the students' consonants and vowel acquisition, consonant group acquisition, swallowing and epenthesis. In the aspect of supra-segment acquisition, the author mainly strengthens the learner's accent shift phenomenon, rhythm pattern, the position of the intonation nucleus in the learner's spoken English, the characteristics of tone-pattern, and the segmentation of tone group. We can improve phonetic level of students through stress, intonation, rhythm, weak forms, linking, and reductions, etc. At the same time, we also carry out comparative pronunciation exercises on some confusing voices. Like the training of listening, speaking, reading and writing, the content of phonetic teaching is comprehensive training for students from form to function, and from micro to macro. Students practice and consolidate phonetics through oral activities such as personal activity, group discussion, imitation, and play.

\section{B. Research Results and Data Analysis}

The questionnaire survey lasted for three months when 300 questionnaires were distributed and 283 valid papers were collected. The survey results show that in the survey of the importance and degree of emphasis of the phonetic intonation in the learning process, those who considered that the phonetic intonation is "very important" and "more important" accounted for $97.33 \%$. In the degree of emphasis, the ratio of "much attention" and "higher emphasis" is $52.47 \%$. It can be seen that most learners have noticed the importance of phonetic intonation and paid more attention to the practice of phonetic intonation. However, from the perspective of the degree of understanding of the importance of phonetic intonation and the importance attached to phonetic intonation, the two are not completely proportional, which means that although students know that phonetic intonation is important for English learning, the time and effort spent here is not enough. Among the three questions about the satisfaction of their own phonetic intonation, the proportion of "unsatisfactory" or "not satisfied" to their own phonetic intonation reached $50.92 \%$. Students who choose "general" account for $28.73 \%$. These students do not have an accurate judgment on their phonetic features, or do not know how to evaluate their own phonetic problems. Those who are satisfied or less satisfied with one's pronunciation and intonation accounts for less than one-third. In the survey of the main problems in the current English phonetics, students have problems in all aspects, but in terms of the problems in differences between the segmental phonemes such as vowels, consonants and tones, students believe that they have more problems with supersegmental phonemes such as liaison, sentence stress, sentence rhythm and intonation. In terms of such problems, the author has recorded the materials read by 250 students in the final stage of the speech survey by setting up a schoolwide phonetics and intonation elective course and a phonetic module embedding teaching experiment. It mainly calculates the mistakes in pronunciation of students such as single tone (vowel and consonant), word stress, sentence stress (weak form), liaison, and intonation, etc. From the statistical results, the error rate of 20 monosyllabic pronunciations is about $25 \%$, and the rate of word rereading error is around $20 \%$, but the average error rate in sentence stress, liaison and intonation has reached more than $70 \%$, which is consistent with the results of the questionnaire survey.

In the survey of the reasons for the students' phonetic problems in the questionnaire for teacher part, the author designed the problems aiming at the emphasis on teaching of phonetic teaching, the problems found and the teacher's mastery of phonetic theory. 150 questionnaires were issued, and 101 valid questionnaires were collected. Among the questions related to the importance of phonetic teaching in the effective questionnaire, nearly $71.37 \%$ of the teachers said that they did not pay enough attention or paid attention to the phonetic teaching. In terms of the phonetic problems found, $100 \%$ of the teachers believe that students have serious or relatively serious problems in different aspects. In the answers to the teachers' phonetic theory knowledge, nearly $50 \%$ of teachers answered that they master 
insufficient knowledge of English and Chinese phonetic systems. Through questionnaire surveys, teachers generally believe that the main reason for the existence of phonetic problems are the lack of phonetic training previously (junior high school, high school) and currently, the serious influence of mother tongue and the insufficient attention of students. This is consistent with the reasons why the students lacked phonetic knowledge and the poor phonetic features in the process of setting up a phonetics elective course. Another important reason summarized by this part of the questionnaire is that although most teachers reflect that they pay more attention to phonetics teaching and learning, some teachers said that they have not been systematically trained in phonetics or phonology, and nearly $40 \%$ of teachers don't understand the differences between English and Chinese phonetic systems, so they can't systematically improve students' phonetic cognition and effective train them in the classroom of college English, which further increases the rigidity of students' speech.

\section{Problems Found During the Course of the Speech Teaching Experiment and After the Course}

- Students' English pronunciation errors mainly focus on confusing long vowels and short vowels [i:] and $[\mathrm{i}], \quad[\mathrm{u}:]$ and $[\mathrm{u}], \quad[\mathrm{a}:]$ and $[\Lambda]$; confusing monophthong and diphthong [æ] and [ai], [i:] and [ei]; confusing diphthongs [eə] and triphthong [aiə]; confusing consonants $[\mathrm{s}]$ and $[\theta]$ or $[\theta]$ and $[\mathrm{z}],[\mathrm{w}]$ and [v], [ts] and [t $\left.\int\right]$; they have no concept of consonants such as plosives, and nasal sounds, etc.; the understanding of liaison, stress and weak and intonation is even insufficient, and the error rate is high; the degree of mastery of pronunciation and intonation is not optimistic.

- $85 \%$ of students think that English pronunciation is very helpful for their English learning, and they are very willing to learn and practice English pronunciation, but at the same time $68 \%$ of students said that English pronunciation is difficult. A considerable number of students gradually lose their motivation during the learning process from the very beginning, and some give up learning at the end. Therefore, students need voice teaching, but how to carry out phonetic teaching, mobilize the enthusiasm of students' phonetic learning, and maintain students' enthusiasm for phonetic learning to ensure the learning effect is the primary problem solved in college English phonetics teaching.

- With the reform of college English, our school, like many other schools, is reducing the hours and credits of college English. The content of the course cannot be guaranteed within the prescribed time, so less time can be used for phonetic teaching and the teaching effect is difficult to guarantee. In addition, college students are already adults. They have formed an inherent pronunciation pattern in the initial stage of English phonetic learning. Coupled with the negative transfer of mother tongue or dialect, it is quite difficult to comprehensively and thoroughly correct the pronunciation, which requires a lot of training for a long time it is also very difficult to achieve a good result.

\section{Summary and Feedback of the Students in the Interview}

- Through phonetic learning, the accuracy of pronunciation is improved and the pronunciation is more standardized. When they meet new words, they can quickly read them according to the phonetic symbols. Reciting words based on phonetic symbols improves the efficiency of reciting words and saves time. Understanding the accuracy of word pronunciation is also very helpful for improving listening ability. Then they become confident about oral expression and become more willing to communicate in English.

- In the course of phonetic teaching, the teacher should select a textbook with appropriate difficulty, and give targeted pronunciation exercises in the classroom. The content of lecture should not be limited to the pure imitation practice according to book, and the teacher should edit some relevant paragraphs suitable for the pronunciation rules learned in the actual practice in the phonetic class from English books and newspapers. Student had better to participate in it, so that the teacher can accurately understand students' inaccurate pronunciation in imitation, and guide the students in the phonetic imitation.

- The teaching form can be diversified. In addition to the presentation of PPT and the use of WORD documents, video files can be played in the class (the teaching value should be high, and had better suit the students' interest), which is closely related to the teaching of speech in order to achieve the teaching purpose of interesting teaching and inspiring students' innovative thinking. Therefore, students can be motivated to actively study phonetics in their spare time, and to cultivate the pronunciation under the influence of movies and other works. They can also promote the form of the phonetic imitating contest to the daily classroom teaching.

- In the process of teaching, students should combine their personal special problems. For example, the difficulties in phonetic learning between southerners and northerners are different, and the difficulties encountered by people in the same region are different. Since the phonetic class plays an important role in the study of English, the original recording of their pronunciation should be recorded when the university students enter the campus (that is the original ecological recording performed without any theoretical infusion) to create a phonetic card for the students, which records the student's name, source, dialect, and typical pronunciation difficulties. As the content of the lesson is deepened, the student's recordings are regularly scheduled and checked until the student's pronunciation is up to standard. 
- The teaching rhythm is fast. The teacher finishes all the voice-related knowledge in the two-week class, so that everyone can't afford it, and can't understand the key and difficult points in explanation thoroughly. It is recommended that the course should be extended throughout the semester. It would be better if the phonetic class can be separated from the listening and speaking class. This makes learning more systematic and easier, and everyone can maintain their interest and motivation in learning and learn better.

- Some teacher's own pronunciation is not particularly good, or the local accent is more obvious. Their demonstration of characteristics of phonetic pronunciation is inaccurate, which is a problem that cannot be ignored. It is recommended that teachers improve their professional level and give positive facilitation to students.

\section{THE ENLIGHTENMENT AND COUNTERMEASURE OF IMPROVING THE QUALITY OF PHONETIC TEACHING IN COLLEGE ENGLISH}

The English pronunciation learning of non-English majors in private colleges is not optimistic, and their phonetic level is not very satisfactory. In order to achieve effective communication through language, students' phonetic learning needs to be further strengthened. From school to English teachers, we should pay attention to phonetics.

\section{A. Fully Understanding the Student's Phonetic Status}

Before the phonetic teaching, the teacher must first understand students' shortcomings in pronunciation and intonation, and then guide and train them in a targeted manner. Only in this way can they get twice the result with half the effort; in the phonetic teaching, the teachers should carry out systematic training in the pronunciation skills and precautions of the English phonetics and conduct the training through a combination of theory and practice as much as possible. After the phonetic teaching, the teacher should follow up the situation of the students' phonetic learning and find out the problems in a timely manner.

\section{B. Paying Attention to Phonetic Teaching, Including It in the Teaching Plan, and Setting up Phonetic Courses}

At present, there are no plans for phonetic teaching and corresponding class schedules in our school's syllabus and teaching plan. The attempt of phonetics embedded teaching practice shows that the teaching of phonetics should be considered in the teaching plan of college English teaching and carried out systematically.

When new student enters school, we should plan a systematical phonetic test register for a month or longer time. After the official start of the semester, we can set up a special phonetic compulsory course for non-English majors, and continue to offer a phonetic elective course to enable students to basic knowledge and basic skills of English pronunciation in the first stage, master the correct pronunciation, intonation and reading skills, learn to identify correct and wrong pronunciation and intonations, and understand the reasons for mistakes. At the same time, the students' English pronunciations are assessed in stages and the pronunciations before and after the training are recorded. This can help teachers to diagnose each student's phonetic errors, provide targeted guidance, and help students to have a clear comparison of their phonetic changes before and after training.

\section{Developing a Teacher Phonetic Training Program to Provide Teachers with Opportunities to Improve Their Phonetic Level}

The key to strengthening English phonetics teaching and improving the quality of phonetic teaching is teachers. Classroom English of English teachers is one of the main sources of students' English pronunciation. Teachers should ensure the "quality" and "quantity" of classroom English, so that students can get correct second language input. Of course, phonetic training for teachers and phonetic training for students are different at the starting point. Therefore, it is recommended to hire a foreign teacher with a good accent, preferably a foreign teacher who has experience in phonetic teaching.

\section{According to the Specific Phonetic Teaching Objectives, Selecting the Appropriate Phonetic Materials for Students}

Our school has a complete set of teaching multimedia equipment, and students also have listening equipment. Under such good conditions, phonetic textbooks with audio or video should be selected to enable students to clearly understand the changes in mouth shape, tongue position and airflow during pronunciation. In addition, attention should be paid to the fun of the textbooks, so that students can learn phonetics more effectively in a relaxed and enjoyable learning atmosphere.

\section{E. Using Modern Technology to Improve Students' Ability to Learn Independently}

Because the time of college English teaching is very limited, the teacher does not have enough time to conduct phonetic training for the students. The traditional college English teaching mode is limited to classrooms and books. Therefore, the teachers should learn to use modern equipment and high-tech products such as computers and mobile phones, rely on a variety of mobile information teaching tools, such as the blue ink cloud class, etc., to set up a phonetic learning group through the combination of in class and after class, and provide students with some phonetic learning materials, etc., so that students can take full train. Teachers can also ask students to practice their pronunciation for a specified number of hours, and appropriately carry out activities such as film dubbing and outdoor speech, which can both train pronunciation and stimulate students' enthusiasm for English learning. 


\section{CONCLUSION}

In short, students' English pronunciation level has a great influence on students' interest and enthusiasm in English learning. By improving students' phonetic level, students' listening and speaking ability is improved. Therefore, college English teachers should actively explore curriculum design and classroom teaching, use modern technology to improve students' self-learning ability of speech, and then promote students' comprehensive ability in English application, especially the improvement of listening and speaking ability, so that they can really apply what they have learned.

\section{REFERENCES}

[1] Cruttendens, A. Gimson's Pronunciation of English [M]. London: Edward Arnold Publishers, 2001.

[2] Jenkins J. A sociolinguistically based, empirically re-searched pronunciation syllabus for English as an interna-tionallanguage [J] . Applied Linguistics, 2002, 23 (1): 83 -103.

[3] Chen Hua. Research on the characteristics of English tonal pattern in Chinese students' reading English [J]. Modern Foreign Languages, 2006(4): 418-425.

[4] Chen Hua, Sun Xinping, Zhang Ying. The Importance, necessity and effectiveness of English intonation awareness training[J]. Foreign Languages Research, 2008(2): 135-139.

[5] Guo Yabin. A review of Flege's speech learning model[J]. Journal of Taiyuan Teaching College, 2006,(6): 71-73.

[6] Luo Lisheng, Zhang Laixiang. Review of English phonetic teaching and suggestions on current English phonetic teaching [J]. Foreign Language and Their Teaching, 2002, (10): 21-23.

[7] Wang Lifei, Sun Xiaokun. Progress in Research on foreign second language phonetic acquisition [J]. Foreign Language and Their Teaching, 2007, (4): 25-29.

[8] Wen Qiufang, Wang Lifei. Empirical research on Chinese English learning strategies for 20 years[J]. Foreign Languages and Literature, 2004, (1): 39-45. 